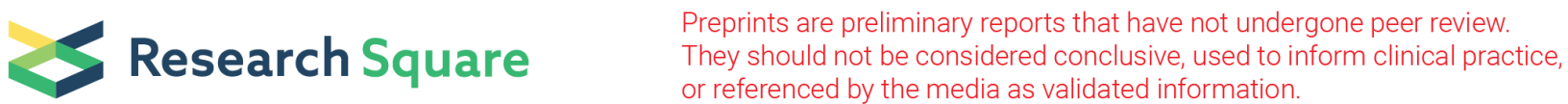

\section{Impact of body composition on physical fitness components in the Mexican Navy: is overweight an issue?}

\section{Laura Sànchez-Chapul ( $\square$ lchapul@yahoo.com )}

Instituto Nacional de Rehabilitacion Luis Guillermo Ibarra Ibarra https://orcid.org/0000-0002-4268-2279

Jesús Fernando Valencia-León

Instituto Nacional de Rehabilitacion Luis Guillermo Ibarra Ibarra, Secretaria de Marina

Mario Acevedo-Mora

Instituto Nacional de Rehabilitacion Luis Guillermo Ibarra Ibarra

Zendy F Fuentes-Corona

Instituto Nacional de Rehabilitacion Luis Guillermo Ibarra Ibarra

Erika Estrada-Camarena

Instituto Nacional de Psiquiatria Ramon de la Fuente Muniz

José Ubaldo Baños-Vázquez

Secretaria de Marina

Egner Hernández-Zamudio

Secretaria de Marina

José Alejandro Rangel-Sánchez

Secretaria de Marina

Israel Gutiérrez-García

Secretaria de Marina

\section{Gabriela A Martínez-Nava}

Instituto Nacional de Rehabilitacion Luis Guillermo Ibarra Ibarra

Sigifredo Salgado-Aguilar

Secretaria de Marina

Liliana Téllez-Cárdenas

Secretaria de Marina

Diego Mirabent-Amor

Instituto Nacional de Rehabilitacion Luis Guillermo Ibarra Ibarra

José Gilberto Fanco-Sánchez

Instituto Nacional de Rehabilitacion Luis Guillermo Ibarra Ibarra

Luis A Bonilla-Arcuate

Secretaria de Marina

Alexandra Luna-Angulo

Instituto Nacional de Rehabilitacion Luis Guillermo Ibarra Ibarra

Ámbar López-Macay 
Instituto Nacional de Rehabilitacion Luis Guillermo Ibarra Ibarra

\section{Research}

Keywords: body mass index, cardiorespiratory fitness, body composition, aerobic capacity, combat readiness, Mexican Navy

Posted Date: April 7th, 2020

DOI: https://doi.org/10.21203/rs.3.rs-21073/v1

License: (c) (i) This work is licensed under a Creative Commons Attribution 4.0 International License. Read Full License

Version of Record: A version of this preprint was published at Cogent Medicine on January 1st, 2020. See the published version at https://doi.org/10.1080/2331205X.2020.1807083. 


\section{Abstract}

Background. Appropriate physical fitness components and body composition are required to overcome dangerous situations during sea rescues and in the first line of combat in the Mexican Navy.

Aim of the study. To analyze the impact of body composition on physical fitness components such as cardiorespiratarory fitness and muscle strength-resistance of marines, rescue swimmers, and divers of the Mexican Navy classified as overweight.

Methods. BC was assessed by two BMI cutoff points (WHO and military); body fat percentage and muscle mass percentage, and waist circumference were determined by anthropometry. Cardiorespiratory fitness was assessed by the Course-Navette test and MSR by a 1-minute maximal effort of push-ups, sit-ups, and bench presses.

Results. We found significant differences in medians of physical fitness components and body composition among groups $(p<0.001)$. The WHO and military BMI showed $59(54 \%)$ and $16(15 \%)$ individuals as overweight, respectively. Marine instructors showed the highest percentage of men to be overweight, 24 (41\%) (WHO) at the expense of good muscle mass percentage but high body fat percentage according to age. All groups showed cardiorespiratory fitness adequate for their age, but only $26(51 \%)$ and $14(24 \%)$ classified as normal and overweight (WHO), respectively, had good cardiorespiratory fitness $(p=0.003)$.

Conclusions. Personnel classified as overweight had good body composition at the expense of high body fat percentage but adequate muscle mass, which could be adequate for their operational tasks; but their cardiorespiratory fitness, although good for their age, is still below the ideal value for military physical activity.

\section{Background}

Overweight, obesity, and inadequate physical fitness in active naval personnel are critical variables that impact directly on the health and wellbeing of service members, military readiness, and the costs associated with medical care and early attrition. The objective of the admission process of civilians to naval discipline is to select recruits that can meet the body composition and physical fitness standards of the Mexican Navy.

The Mexican Marine Infantry (MMI) and the School of Search and Rescue and Diving (ESBUSREB, for its acronyms in Spanish) are two Mexican Navy operative units whose mission is to carry out special amphibious operations, by executing high-risk practices (military diving, parachuting, vertical descent, urban combat, sniping, and marine rescues) and physically demanding tasks, such as lifting, handling, and carrying aditional loads ${ }^{1}$.

The high variability of external and internal factors that intervene in the actions of rescue in the marine environment or as the first line of combat requires professionals highly qualified physically, technically, and psychologically to successfully overcome a wide range of dangerous situations since human life depends on them ${ }^{2}$. Therefore, it is necessary to carry out regular physical examinations and fitness tests to ensure that naval personnel are prepared for the physical and mental demands of military service ${ }^{3}$. 
The Annual Medical Exam of the Mexican Navy is an official evaluation of physical health that monitors naval personnel to determine their physical fitness and body composition ${ }^{4}$. The Annual Medical Exam 2019 reported $7320(13 \%)$ cases as overweight and 5459 (10\%) with obesity. This classification was made by calculating the BMI by bioelectrical impedance analysis measures only, taking as reference military BMI cutoff points, which establish that personnel with a BMI $<28$ is to be classified as normal weight, $\mathrm{BMI}$ of 28 to 29.9 as overweight, and $\mathrm{BMI} \geq 30$ as obese (grade I- III) ${ }^{4}$. These cutoff points are broad if we compare them with those established by the WHO and underestimates cases of overweight with good body composition; therefore, this study was aimed at determining the body composition of Mexican naval personnel classified as overweight, and to analyze its impact on physical fitness components such as cardiorespitarory fitness and muscle strength-resitance, characteristics that have not been determined in this population.

\section{Methods}

\section{Participants}

This was an analytical and transversal study to determine the physical fitness components and body composition of marines, rescue swimmers, and divers of the Mexican Navy and to analyze the impact of overweight on cardiorespitarory fitness, muscle strength-resitance, and body composition. Individuals in this study were those who started the Training Course for Recruits of the Mexican Navy (CCRAM, for its acronym in Spanish) from the MMI, enrolled in the courses of surface rescue and helicopter rescue swimmers; as well as divers and underwater works from the ESBUSREB. We recruited 110 men, aged 18 to 49 years, distributed as follows: 50 participants from MMI [25 marine instructors (MI) and 25 marine recruits (MR)], and 60 from ESBUSREB [10 surface rescue swimmers (SRS), 7 surface rescue and helicopter swimmers (SRHS), 8 helicopter rescue swimmers (HRS), 10 advanced and 14 beginner divers/underwater works (ADUW and BDUW, respectively) and 11 swimming and diving instructors (SDI)].

Physical fitness criteria were determined prior to initial training, evaluating cardiovascular risk, cardiorespiratory fitness (CRF) ( $\mathrm{VO}_{2}$ max/METs), and muscle strength-resistance (MSR) in upper and central train, as well as body composition (BC) calculating body fat percentage (BFP) and muscle mass percentage (MMP) by anthropometrical measurements.

This study was approved by the Research and Ethics Committees of the Instituto Nacional de Rehabilitación "Luis Guillermo Ibarra Ibarra" (CONBIOETICA-09-CEI-03120171207). All naval personnel were informed of the benefits and risks of the investigation prior to signing an institutional informed consent approval document to participate in the study.

\section{Determination Of Physical Fitness Criteria}

Stratification of cardiovascular risk. This was done through exercise and clinical evaluation including spirometry and electrocardiogram performed prior to the initial training on the same day. 
Cardiorespiratory fitness. It was evaluated by the Course-Navette test, which is an indirect estimate of the maximum oxygen consumption $\left(\mathrm{VO}_{2} \max \text { in } \mathrm{mL} \mathrm{kg}^{-1} \mathrm{~min}^{-1}\right)^{5}$. All tests were done in groups of eight participants and were performed on the same day and the same running track to improve the test's precision and achieve standardization among the participants. Cardiorespiratory fitness was converted to METs when necessary, dividing the $\mathrm{VO}_{2}$ max values by $3.5^{6}$. We used the US CRF standards for firefighters to categorize CRF of naval personnel because there are no CRF standard values for the Mexican naval personnel and because the 12 METs threshold has been already reported".

Evaluation of muscular strength/resistance in upper and central train. The test consists of one event of 1minute maximal effort of push-ups, sit-ups, and bench press. The result of the test was expressed as a number of consecutive successful repetitions for 60 seconds. Participants were evaluated according to the results reported in the Canadian Physical Activity, Fitness \& Lifestyle Approach and YMCA Fitness Testing and Assessment Manual ${ }^{8,9}$.

\section{Body Composition}

Body composition was assessed prior to initial training and for each group, through three different indices calculated by anthropometric measurements: (a) BMI with the cutoff points proposed by $\mathrm{WHO}^{10}$ and the Military classification ${ }^{5}$; b) body fat percentage and muscle mass percentage calculated by the 25-skinfold protocol according to the guidelines of the International Society for the Advancement of Kineanthropometry (ISAK); and (c) waist circumference (WC).

Anthropometric measurements. Anthropometric measurements were used to assess weight, height, diameters, circumference, and skinfolds to determine the BC according to the ISAK guidelines ${ }^{11}$. The measurements were obtained, on the same day, in the same session to avoid technical measurement errors. Naval personnel had a 12-hour fast, without lotions or body oils on their bodies, and without having done any type of exercise, and using only shorts. Twenty-five anthropometric variables were measured, of which 21 were part of the restricted profile of ISAK, and 4 additional variables (maximum waist circumference, forearm fold, chest fold, and left abdominal fold). Skinfold thicknesses were measured using calibrated skinfold calipers (Slim Guide) and a short-branch anthropometer (Cescorf). The measurements were made by two anthropometrists certified with level 2 by ISAK.

Body mass index. Height was measured using a portable stadiometer (Seca Model 213, Hamburg, Germany) and the body mass $(\mathrm{kg})$ using a calibrated digital flat scale (Omron Brand model Hbf-514 C). Body mass index was calculated by dividing weight (in kilograms) by height (in square meters) $\left(\mathrm{kg} / \mathrm{m}^{2}\right)$. Naval personnel was classified according to: a) the BMI cutoff points of WHO as low weight $\left(<18.5 \mathrm{~kg} / \mathrm{m}^{2}\right)$, normal weight (18.5-24.9 kg/m²), overweight (25-29.9 kg/m²), obesity grade I (30-34.9 kg/m²), obesity grade II (35$\left.39.9 \mathrm{~kg} / \mathrm{m}^{2}\right)$, and obesity grade III ( $\left.\geq 40 \mathrm{~kg} / \mathrm{m}^{2}\right)$; and b) the BMI cutoff points described in articles 226 and 226-Bis of the Mexican military classification, which establish that personnel with a BMI of 28 to 29.9 will be classified within the list of conditions (overweight), BMI of 30-34.9 in third category (obesity I), BMI of 35-39-9 second category (obesity II), and BMI $\geq 40$ in first category (obesity III) ${ }^{4}$. 
Muscle mass and body fat percentage. Muscle mass percentage was calculated using the Drinkwater and Ross Eq. $1^{2,13}$. The MMP reference used was from 46.7 to $51-5 \%$ for men who practice triathlon ${ }^{6}$, because a triathlon combines extreme physical and psychological resistance, aspects that are also very important in naval discipline. Body fat percentage was calculated by the Siri formula from the 3-fold Jackson and Pollock formula for body density ${ }^{14}$. The body fat percentage reference used was that established by the American College of Sports Medicine, whose values are: 7.9-10.5\% (18-29 years), 12.4-14.9\% (30-39 years), 15$17.5 \%$ ( $40-49$ years) ${ }^{15}$, and BFP $\geq 25 \%$ for male naval personnel ${ }^{4}$.

Waist circumference. Waist circumference was measured with a measuring tape (Rosscrafty Lufkin) according to the ISAK protocol for the diagnosis of metabolic diseases for men (healthy $\leq 90 \mathrm{~cm}$; at risk > $90 \mathrm{~cm})^{16}$.

\section{Statistical Analysis}

Descriptive analysis was carried out estimating the median of age, BMI, BFP, MMP, and CRF. The distribution of overweight (WHO and military cutoff points), WC BFP, MMP, WC, CRF, and muscular strength (percentage of individuals above and below the average number of sit-ups, bench press and push-ups) between overweighed and normal-weighed individuals among groups was performed by Fisher's exact exam. We assessed the association between physical fitness components and body composition by linear and logistic regression models. Best BFP, BMI, MMP, and WC cut-off points, which differentiate fit and unfit individuals, were estimated by receiver-operating characteristic (ROC) curves. All statistical analyses were performed with the STATA v.14 software (College Station, TX, USA) considering a significance level of 0.05 .

\section{Results}

We recruited 110 men with a median age of 28 (18-49) years, BMl of $25.33\left(24.5-27.72 \mathrm{~kg} / \mathrm{m}^{2}\right)$, BFP of 11.85 (9.9-15.6\%), MMP of 46.5 (43.4-50.9\%), and MET values of 11.33 (10.34-12.93). The WC values showed 90 $(82 \%)$ individuals classified as healthy and $20(18 \%)$ with cardiometabolic risk (WC $>90 \mathrm{~cm})$.

The analysis of physical fitness components according to operative groups is shown in Table 1 with significant differences in all physical components except BFP $(p=0.30)$. According to the BMI cutoff points of WHO, 59 (54\%) individuals had overweight, but only $16(14 \%)$ according to the military classification. The marine instructors showed the highest percentage of men in overweight, $24(41 \%)$ and $12(75 \%)$ according to WHO and military classification, respectively, as well as HRS and ADUW, all at the expense of a good distribution of muscle mass and muscular strenght in upper and central train (Table 1). In general, the population showed a CRF adequate for their age, but only $26(51 \%)$ in normo-weight and 14 (24\%) classified as overweight (WHO) had METs $\geq 12(p=0.003)$. Figure 1 shows the cardiorespiratory fitness among groups in normal and overweight (WHO) individuals; being MR the only group that had METs $\geq 12$ in both normal and overweight individuals. The rest of the groups were below (METs $<12)$, highlighting that $13(25 \%)$ of them presented a high percentage of body fat, and only 7 (13\%) good muscle mass (Table 1). The univariate analysis of the $\mathrm{VO}_{2}$ max, age, $\mathrm{BMI}, \mathrm{BFP}, \mathrm{MMP}$, and $\mathrm{WC}$ revealed that $\mathrm{VO}_{2}$ max (METs) was negatively associated with age $(\beta=-0.092, p<0.001)$, BMI $(\beta=-0.15, p<0.001)$, BFP $(\beta=-0.20, p<0.001)$, and WC $(\beta=$ 
$-1.20, p<0.001)$. However, after adjusting data in a multivariate analysis, only age $(\beta=-0.05, p<0.022)$ and $\operatorname{BFP}(\beta=-0.15, p<0.001)$ were negatively associated with $\mathrm{VO}_{2}$ max. The evaluation of the PFC potential as biomarker for CRF showed that BFP had the highest area under the curve (AUC $=0.721, \mathrm{Cl} 95 \%$ ), followed by BMI (AUC $=0.7, \mathrm{Cl} 95 \%$ ). The analysis of the risk of being unfit according to physical fitness components is showed in Table 2.

Table 1

Analysis of physical fitness components according to operative group.

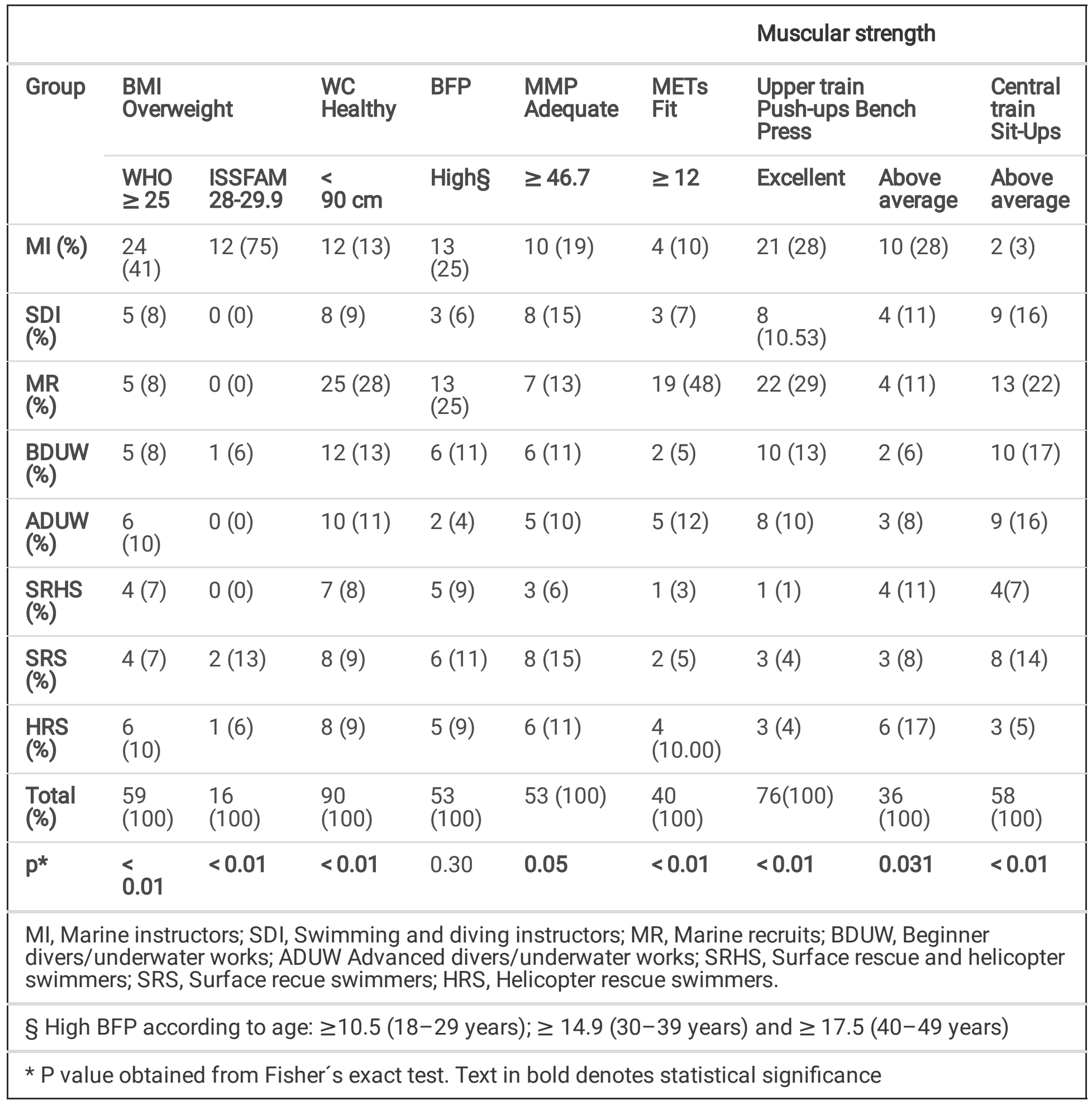


Table 2

Analysis of the risk of being unfit according to physical fitness components

\begin{tabular}{|c|c|c|c|c|c|c|}
\hline \multirow[t]{2}{*}{ PFC } & \multicolumn{6}{|c|}{ Unfit METs (< 12) } \\
\hline & $\mathrm{OR}^{\mathrm{a}}$ & $\mathrm{Cl} 95 \%$ & p & $\mathrm{OR}^{\mathrm{b}}$ & $\mathrm{Cl} 95 \%$ & $\mathbf{p}$ \\
\hline \multicolumn{7}{|l|}{ Age (years) } \\
\hline $30-39$ & 2.47 & $0.93-6.60$ & 0.07 & 1.27 & $0.40-4.07$ & 0.684 \\
\hline $40-49$ & 11.24 & $1.39-90.74$ & 0.023 & 4.14 & $0.45-38.09$ & 0.209 \\
\hline \multicolumn{7}{|l|}{ BMI $\left(\mathrm{kg} / \mathrm{m}^{2}\right)$} \\
\hline Overweight (WHO) & 3.34 & $1.48-7.54$ & 0.004 & 1.44 & $0.53-3.92$ & 0.471 \\
\hline Overweight (ISSFAM) & 10.64 & $1.35-83.9$ & 0.025 & 2.49 & $0.19-32.50$ & 0.486 \\
\hline BFP & 1.27 & $1.11-1.44$ & $<0.001$ & 1.17 & $1.01-1.36$ & 0.038 \\
\hline WC (risk) & 6.58 & $1.44-30.06$ & 0.015 & 1.41 & $0.18-11.21$ & 0.743 \\
\hline
\end{tabular}

\section{Discussion}

Evaluating changes in anthropometrics and body composition in military personnel is important because these changes could affect fitness, performance, and safety ${ }^{17}$. This study determined, for the first time, the body composition and physical fitness components of marines, rescue swimmers, and divers of the Mexican Navy and demonstrated that personnel in overweight had good body composition at the expense of high BFP, adequate MMP and CFR. Furthermore, at age above 40-49 years, the military classification of overweight, cardiometabolic risk (WC >90 cm), and BFP were good predictors for having a poor physical fitness in the Mexican Navy.

Obesity has been one of the concerns of our country and of the Mexican Navy because it is a condition associated with diabetes and cardiovascular diseases ${ }^{18}$, conditions that are generating high costs of medical attention and compromise the performance of naval personnel. The prevalence of overweight and obesity in active military service members ${ }^{19}$ and veterans ${ }^{20}$ of the United States and Mexican Navy has been estimated based on BMI only, however BMI can overestimate overweight and obesity among Armed Forces personnel, so it is important to know the body composition.

We observed that military classification based on BMI underestimates cases of overweight in the Mexican Navy; however, it is important to highlight that the analysis of body composition allowed us to identify cases of overweight with good distribution of muscle mass but high body fat percentage, which, depending on the naval operative tasks, could be considered adequate. Therefore, it is important to analyze the impact of body composition in infantry, maritime rescue operations, and diving/underwater works. 
Mexican marines presented a high BFP, a characteristic that could contribute to increase the thermal isolation of the body and make metabolic adaptations to obtain energy in cases of extended semistarvation during operative activities ${ }^{18}$. In line with this idea, in infantry soldiers of the US Army, the BMI and body fat are strongly correlated $(r=0.86)^{21}$ and, in the military environment, a higher fat percentage is advantageous in a starvation situation and for sensitivity, performance, and survival in the cold ${ }^{18}$. Besides, our MR presented a low muscle mass percentage (43.4\%), a condition that represents a disadvantage because it is not the most appropriate to meet the physical demands of CCRAM and because many of the operational tasks in infantry are often performed wearing combat gear and a body armor, which increase the weight of the load; thus, they require a lot of energy, adequate muscle mass, and muscle strength to accelerate the lower limbs to displace the total body weight ${ }^{22}$. It is important to consider that this group is formed by young civilians who had just recently joined the Mexican Navy and although having met the entry standards (BMI $\leq 24.9 \mathrm{~kg} / \mathrm{m}^{2}$ ), their body composition (high BFP and low MMP) is not impacting negatively their physical fitness because they had the highest number of fit individuals (METs $\geq 12$ ). However, it is important for this group to work in improving muscle quality and muscular strength in order to improve their physical performance and avoid muscle injuries; considering that increasing the weight of the load has been reported to influence negatively the physical performance of soldiers during tasks of longer and shorter duration ${ }^{22}$.

Our rescue swimmers and divers also had a high BFP, with 78 (71\%) of them without metabolic risk, these facts could represent a physical advantage because a high BFP decreases the body's need to release more energy for flotation, providing a greater buoyancy, and increasing thermal resistance to cold ${ }^{23}$, not hampering swimmers performance ${ }^{25,26}$. Reports indicate that during a maritime rescue operation, the distances covered by the swimmers towards the victims depend on the currents, tides, waves, wind, and water temperature, representing greater energy expenditure per distance unit for them than for terrestrial locomotion ${ }^{23,24}$. When search and rescue swimmers descend into the water, they not only have to overcome the impediments of the aquatic environment to reach the victim, but they must also carry their own weight, that of the victim, and their protective components and equipment, so they require an optimal level of muscular strength and physical fitness ${ }^{24}$.

The HRS, SRS, SDI, had the highest MMP compared to SRHS, and despite their training during 3 (SRS and HRS) to 6 months (SRHS) to strengthen the upper trunk and core muscles; only SDI had an excellent upper and central train strengthening. Hence, it is imperative that these groups work on improving muscular strength and power, particularly in their arms and trunk because these characteristics are essential components of the explosiveness needed to reach and drag their victims during rescue operations at the sea $^{27}$. It is important to mention that the rescue swimmers group presented the smallest percentage of individuals with good physical fitness.

The $\mathrm{BC}$ and physical fitness level of divers and underwater works correspond to Navy personnel that previously had military training, but with a low MMP $(45 \%)$ at the beginning of the diving course; however, at the end of it ( 1 year later), they were lean and fit men who gained muscle mass, had less fat mass, and reached a good physical fitness level (METs $\geq 12$ and MMP 46.7-51.5\%), indicating that the tactical and physical training course taught by the ESBUSREB was beneficial for those overweight young men in this group (data not shown). The benefits of $\mathrm{BC}$ and aerobic performance due to military training has been 
reported also in other military populations ${ }^{28}$. The physiological demands of swimming are quite different from those of diving, thus, body composition may differ between these two disciplines. Unfortunately, there are few studies that have analyzed the relationships between body composition and swimming and diving performance in athletes or military personnel ${ }^{25,26}$; therefore, additional research on this field is needed to help determine optimal levels to maximize performance, prevent injuries, and ensure overall health in rescue swimmers and divers from ESBUSREB of the Mexican Navy, as well as to warrant the success of rescue missions at sea and underwater works.

It is important to emphasize that swimmers, divers, and marines that did not meet BC Mexican Navy standards at the beginning of their training courses, but were in the process of improving physical fitness and $\mathrm{BC}$ during the training, could be able to excel in naval-relevant tasks, which would make it inappropriate to exclude them from naval services. Additionally, it is necessary to implement tests focused on evaluating other important aspects, in addition to those already evaluated by the Mexican Navy (aerobic conditioning, muscle strength, and endurance, and body composition) such as: flexibility, muscular power and agility, balance, coordination, speed and time of reaction ${ }^{29}$; finally, it should be considered to include anthropometry measures in the Annual Medical Exam to asses body composition to correctly classify military personel with overweight and for future naval population studies ${ }^{30}$.

Finally, BFP and WC were the most important predictors for having poor physical fitness; therefore, the recommendation to improve weight and fitness in the Mexican Navy's training programs is to increase CRF and muscle resistance-strenght, with changes in lifestyles associated with specific nutritional demands that would favor the success in maritime rescue operations, diving and underwater works, and completion of infantry tasks.

Our study has some limitations. First, the number of participants was limited because only few of them request to take the courses. Second, women could not be included because of the small number of women with operational tasks in the Mexican Navy. Third, there are few studies that have analyzed the body composition and evaluated the physical fitness of rescue swimmers and divers in military personnel, which limits the benchmarks to compare our population.

Our major strength is that it is the first study that highlights important variables, such as body composition and physical fitness components among Mexican naval personnel, providing also a reference group for further research. There is also a gap in the literature between body composition and swimming/diving performance, which opens the door for further studies.

\section{Conclusion}

The analysis of body composition of marines, swimmers, and divers allowed us to identify cases of overweight (WHO) with a good body composition at the expense of high body fat but adequate muscle mass; characteristics that could be considered adequate depending on the naval operational tasks. However, their cardiorespiratory fitness, although good for their age, is still below the ideal value for military physical activity.

\section{List Of Abbreviations}


PFC, Physical fitness components

BC, Body composition

BMI, Body mass index

WHO, World Health Organisation

METs, Metabolic Equivalents

CCRAM for its acronym in Spanish, Training course for recruits of the Mexican Navy

MMI, Mexican Marine Infantry

ESBUSREB for its acronym in Spanish, School of Search and Rescue and Diving

MI, Marine instructors

SDI, Swimming and diving instructors

MR, Marine recruits

BDUW, Beginner divers/underwater works

ADUW, Advanced divers/underwater works

SRHS, Surface rescue and helicopter swimmers

SRS, Surface recue swimmers

HRS, Helicopter rescue swimmers

MSR, Muscle strength-resistance

BFP, Body fat percentage

MMP, Muscle mass percentage

CRF, Cardiorespiratory fitness

WC, Waist circumference

ISAK, International Society for the Advancement of Kineanthropometry

AUC, Area under the curve

\section{Declarations}


This study was approved by the Research and Ethics Committees of the Instituto Nacional de Rehabilitación "Luis Guillermo Ibarra Ibarra"(CONBIOETICA-09-CEI-031-20171207). All naval personnel were informed of the benefits and risks of the investigation prior to signing an institutionally approved informed consent document to participate in the study.

\section{Consent for publication}

Not applicable

\section{Availability of data and materials}

The datasets used and/or analysed during the current study are available from the corresponding author on reasonable request.

\section{Competing interests}

The authors declare that they have no competing interests

\section{Funding}

Not applicable

\section{Competing Interests State}

The authors declare that they have no competing interests

\section{Acknowledgments}

This study was supported by Instituto Nacional de Rehabilitación "Luis Guillermo Ibarra Ibarra" and by the Mexican Navy. We thank José L. Andrade-Cabrera, Daniela García-Miranda, Natsuko Paniagua-Díaz, Miriam Espinoza-Rivera, Dulce Díaz-Rosas, Alicia Ortega-Mora, and Joel Torres-Beltrán for their technical assistance. The authors alone are responsible for the content and writing of the paper.

\section{Authors's contributions}

$\mathrm{LSCH}$, conceived of the presented idea and carried out the data analysis and wrote the manuscript with support from EEC, JUBA and GAMN. JFL and MMA carried out the anthropometric measurements to determine body composition and contributed to the final version of the manuscript. ZFFC, DMA and JGFS carried out the tests to determine physical fitness criteria. JUBA, EHZ, JARS, IGG, SSA, LTC and LABA participated in recruiting naval personnel and were involved in planning and supervising the organization of the work. ALA and ALM participated in coordination and helped to draft the manuscript and contributed to the final version of the manuscript. GAMN and EEC participated in the design of the manuscript, contributed to the interpretation of the results and performed the statistical analysis.

\section{References}


1. Knapik JJ, Reynolds KL, Harman E. Soldier load carriage: historical, physiological, biomedical, and medical aspects. Mil Med. 2004;169:45-56.

2. Sargent C, Gebruers C, O’Mahony J. A review of the physiological and psychological health and wellbeing of naval service personnel and the modalities used for monitoring. Mil Med Res. 2017;4:1-28.

3. Afari N, Cuneo JG, Herbert M, Miller I, Webb-Murphy J, Delaney E, et al. Design for a cohort-randomized trial of an acceptance and commitment therapy-enhanced weight management and fitness program for Navy personnel. Contemp Clin Trials Commun. 2019. doi:.

4. Directiva para el Diagnóstico. Prevención y Tratamiento del Sobrepeso u Obesidad del Personal en el Servicio Activo de la Armada de México (Directiva 03).

5. Léger LA, Mercier D, Gadoury C, Lambert J. The multistage 20 metre shuttle run test for aerobic fitness. J Sports Sci. 1988;6:93-101.

6. Garber CE, Blissmer B, Deschenes MR, Franklin BA, Lamonte MJ, Lee IM, et al. American College of Sports Medicine position stand. Quantity and quality of exercise for developing and maintaining cardiorespiratory, musculoskeletal, and neuromotor fitness in apparently healthy adults: Guidance for prescribing exercise. Med Sci Sports Exerc. 2011;43:1334-59.

7. Baur DM, Leiba A, Christophi CA, Kales SN. Low fitness is associated with exercise abnormalities among asymptomatic firefighters. Occup Med. 2012;62:566-9.

8. Canadian Society for Exercise Physiology. Canadian Physical Activity, Fitness \& Lifestyle Approach: CSEP-Health \& Fitness Program's Appraisal \& Counseling Strategy, Ottawa, Ont. Canadian Society for Exercise Physiology, 2004.

9. YMCA of the USA. In. YMCA Fitness Testing and Assessment Manual. Champaing: Human Kinetics; 2000.

10. WHO. Technical Report Series 894. Obesity: Preventing and Managing the Global Epidemic. Geneva: World Health Organization, 2000.

11. Marfell-Jones M, Olds T, Stewart A, Lindsay-Carter LE. ISAK International Standards for Anthropometric Assessment. Glasgow: International Society for the Advancement of Kinanthropometry; 2012.

12. Ross WD, Kerr D. Fraccionamiento de la masa corporal: un nuevo método para utilizar en nutrición, clínica y medicina deportiva. Revista de Actualización en Ciencias del Deporte. 1993;1:3.

13. Drinkwater DT, Ross WD. Anthropometric fractionation of body mass. In: Ostyn M, Beunen G and Simons editors. International Series of Sports Science, Kinanthropometry II. Baltimore: University Park Press; 1980. p. 183.

14. Pons V, Riera J, Galilea PA, Drobnik F, Banquells M, Ruiz O. Características antropométricas, composición corporal y somatotipo por deportes. Datos de referencia del CAR de San Cugat, 1989-2013. Apunts Med Sport. 2015;50:6572.

15. American College of Sports Medicine. ACSM's Guidelines for Exercise Testing and Prescription, 9th Edition. 2014.

16. Macias N, Quezada AD, Flores M, Valencia ME, Denova-Gutiérrez E, Quiterio-Trenado M, et al. Accuracy of body fat percent and adiposity indicators cut off values to detect metabolic risk factors in a sample of Mexican adults. BMC Public Health. 2014;14:341-9. 
17. Friedl K. Body composition and military performance many things to many people. J Strength Cond Res. 2012;26:87-100.

18. Barquera-Cervera S, Campos-Nonato I, Rojas R, Rivera J. Obesidad en México: epidemiología y políticas de salud para su control y prevención. Gaceta Médica de México. 2010;146:397-407.

19. Reyes-Guzmán CM, Bray RM, Forman-Hoffman VL, Williams J. Overweight and Obesity Trends Among Active Duty Military Personnel: A 13-Year Perspective. Am J Prev Med. 2014;48:145-53.

20. Almond N, Kahwati L, Kinsinger L, Porterfield D. Prevalence of overweight and obesity among U.S. military veterans. Mil Med. 2008;173:544-9.

21. Grier T, Canham-Chervak M, Sharp M, Jones BH. Does body mass index misclassify physically active young men? Prev Med Rep. 2015;2:483-7.

22. Jaworski R, Jensen A, Niederberger B, Congalton R, Kelly KR. Changes in combat task performance under increasing loads in active duty marines. Mil Med. 2015;80:179-86.

23. Pendergast D, Zamparo P, di Prampero PE, Capelli C, Cerretelli P, Termin A, et al. Energy balance of human locomotion in water. Eur J Appl Physiol. 2003;90:377-86.

24. López-Cerón A. La operación del Operador de Grúa y el Rescatador. I Curso SAR para pilotos. Madrid: COPAC; 2009.

25. Lowensteyn I, Signorile JF, Giltz K. The effect of varying body composition on swimming performance. J Strength Cond Res. 1994;8:149-54.

26. Mameletzi D, Siatras T, Tsalis G, Kellis S. The relationship between lean body mass and isokinetic peak torque of knee extensors and flexors in young male and female swimmers. Isokinet Exerc Sci. 2003;11:159-63.

27. Sharp RL, Troup JP, Costill DL. Relationship between power and sprint freestyle swimming. Med Sci Sports Exerc. 1982;14:53-6.

28. Vaara JP, Kokko J, Isoranta M, Kyröläinen $\mathrm{H}$. Effects of added resistance training on physical fitness, body composition, and serum hormone concentrations during eight weeks of special military training period. J Strength Cond Res. 2015;29:168-72.

29. Nindl BC, Alvar BA, Dudley R, Favre J, Martin MW, Sharp GJ. MA, et al. Executive Summary From the National Strength and Conditioning Association's Second Blue Ribbon Panel on Military Physical Readiness: Military Physical Performance Testing. J Strength Cond Res. 2015;29:216-20.

30. Shams-White MM, Chui K, Deuster PA, McKeown NM, Must A. Comparison of anthropometric measures in US Military personnel in the classification of overweight and obesity. Obesity (Silver Spring). 2020;28:362-70. .

\section{Figures}




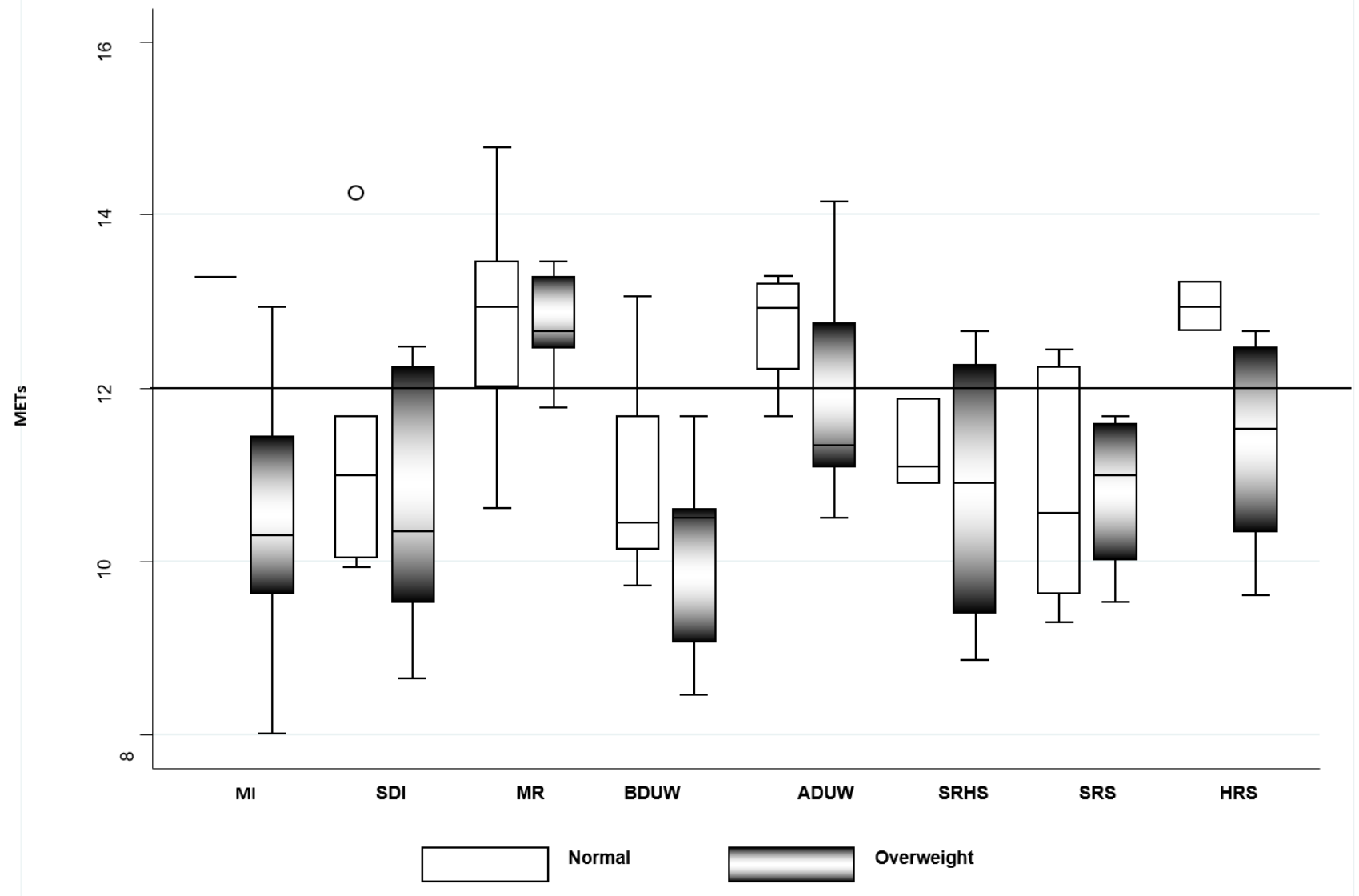

Figure 1

Cardiorespiratory fitness among groups in normal and overweighed individuals according to the WHO classification. 